\title{
Simultaneous Reassembly and Procurement Planning in Assemble-to-Order Remanufacturing Systems
}

\author{
Yosep Oh
}

Sara Behdad * (Corresponding Author)

\begin{abstract}
Assemble-to-Order (ATO) remanufacturing systems deal with decision-making about the number and type of modules ready for reassembly, while managing a high degree of uncertainty in the quantity of incoming end-of-life products. Remanufacturers who adopt the waste stream system often passively accept an unpredictable amount of collected supply in their systems. Also, often they keep various items in their inventory for future reassembly purposes despite the parts depreciation which leverages part values in the second-hand market. To overcome these challenges, this paper proposes a graph-based optimization model for simultaneous reassembly and procurement planning with the aim of determining the type and number of parts that should be reassembled and procured, considering the market demand for both cores and subassemblies. This study articulates the problem employing a network flow graph and integer linear programming (ILP). In addition, the study suggests two key concepts: (1) disposal point, and (2) reassembly threshold. Considering recycling benefits and holding costs, the disposal point helps remanufacturers make proper decisions about the time that they have to dispose of parts that are stored in their inventory. The reassembly threshold makes remanufacturers recognize a tipping point for reassembly process cost where they have to keep parts rather than reassemble them. The application of the proposed method is illustrated using a smartphone example.
\end{abstract}

Key Words: Assemble-to-Order (ATO) Systems; Remanufacturing; Reassembly and Procurement Planning; Integer Linear Programming (ILP); Network Flow Graph; Part Depreciation 


\title{
Simultaneous Reassembly and Procurement Planning in Assemble-to-Order Remanufacturing Systems
}

\begin{abstract}
Assemble-to-Order (ATO) remanufacturing systems deal with decision-making on the number and type of modules ready for reassembly, while managing a high degree of uncertainty in the quantity of incoming end-of-life products. Remanufacturers who adopt the waste stream system often passively accept an unpredictable amount of collected supply in their systems. Also, they often keep various items in their inventory for future reassembly purposes despite the parts depreciation which leverages part values in the second-hand market. To overcome these challenges, this paper proposes a graph-based optimization model for simultaneous reassembly and procurement planning with the aim of determining the type and number of parts that should be reassembled and procured, considering the market demand for both cores and subassemblies. This study articulates the problem employing a network flow graph and integer linear programming (ILP). In addition, the study suggests two key concepts: (1) disposal point, and (2) reassembly threshold. Considering recycling benefits and holding costs, the disposal point helps remanufacturers make proper decisions on the time that they have to dispose of parts that are stored in their inventory. The reassembly threshold makes remanufacturers recognize a tipping point for reassembly process cost where they have to keep parts rather than reassemble them. The application of the proposed method is illustrated using a smartphone example.
\end{abstract}

Keywords: Assemble-to-Order (ATO) Systems; Remanufacturing; Reassembly and Procurement Planning; Integer Linear Programming (ILP); Network Flow Graph; Part Depreciation 
Remanufacturers use various production strategies such as Make-to-Stock (MTS), Make-to-Order (MTO) and Assemble-to-Order (ATO) [1]. In particular, ATO is preferred when a more agile response to customer orders is needed based on assembly systems [2]. In ATO strategy, assembly processes are triggered by the receipt of orders, and until then assembly parts are held in stock [3]. When it comes to remanufacturing systems, this strategy is called Reassemble-to-Order (RATO) where it focuses on inventory control and replenishment policies [4], [5]. The reassembly planning in remanufacturing systems is particularly challenging due to the high degree of uncertainty in the incoming supply, market demand and timing [6], [7].

There are two types of second-market demands in this study: (1) current demands for complete assembly products (end-items); and (2) future demands for end-items and its subassemblies. The former is deterministic in this study since we deal with a certain demand that remanufacturers already have. On the other hand, this paper considers the latter as a non-deterministic factor that is used for obtaining potential revenue when a part is stored in the inventory. The objective of this study is to provide a method for determining the optimal reassembly and procurement plans considering the both two types of demands. One of the major decisions is whether to pursue a certain benefit by reassembling parts and satisfying the current demand or to store parts for future demands.

Remanufacturers often have a limited number of parts in their inventory due to the uncertainty in the amount of incoming supply to remanufacturing facilities [8]. The limited inventory as a result of uncertain number of incoming products brings some difficulties in the reassembly planning. To overcome this situation, the study considers the procurement plan as well as the reassembly plans. The proposed method is applied to a type of ATO systems called multi-component inventory systems, where each component inventory level is controlled to satisfy the demand for an end-item [5]. In ATO systems, the external demand of customers is generally originated at the end-item level only [9]. However, external demands for both subassemblies and end-items are considered in this study. In addition, the part depreciation is adopted to reflect the reduction of part value over time at the secondhand market. 
The problem is solved in two phases: (1) obtaining the potential revenue of storing each part in the inventory; and (2) finding the optimal number of reassembly and procurement for each part. In the first phase, the potential revenue is calculated as an expected value using the demand arrival rate for each part, and its result is fed to the next phase. In the second phase, the problem is modeled using network flow and solved by employing an integer linear programming (ILP). As a parameter, the potential revenue is used in the objective function of the model and a certain demand for end-items is adopted as a constraint in the ILP model. In the ILP model, two types of decision variables are included: (1) the number of reassembly for each part; and (2) the number of procurement for each part. Note that this study only considers a single period since the ILP model for reassembly-to-order planning is established based on a certain current demand. Therefore, the method can be applied repeatedly whenever a new demand is arrived. If a new demand is occurred, the remanufacturer would need a new reassembly-to-order plan and all parameters and variables should be reset.

Several specific terms are used in this study to represent the hierarchical structure of an end-of-life product: core, intermediate, component, and element. A core refers to an intact reassembled product. An intermediate indicates a product module, while a component denotes a part that cannot be disassembled further [10]. Also, the term "element" refers to any item that can be core, intermediate or component. Figure 1-(a) represents a hierarchical structure of seven elements consisting of Core $\theta$, Intermediates 1 and 2, and Components 3, 4, 5 and 6.

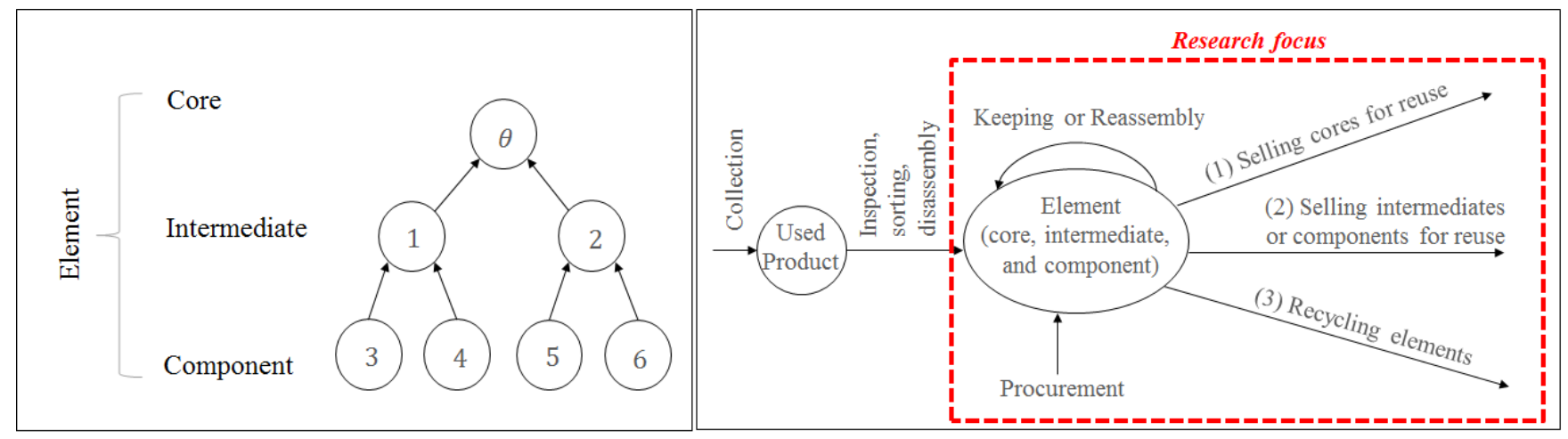

(a) Element structure for reassembly

(b) End-of-life recovery process

Figure 1. (a) Element structure for reassembly and (b) end-of-life recovery process 
End-of-life products are collected and then go through the recovery procedure as shown in Figure 1-(b). After inspection, sorting, and disassembly, elements are reassembled for reusing, keeping in storage or recycling [10]. The focus of the study is on disassembled elements stored in the stock. In other words, we assume that unqualified elements are already removed during disassembly and sorting processes. This means that any operation costs for these processes before reassembly are not considered in the proposed reassembly and procurement plans. In this boundary, remanufacturers can obtain profits in three ways: (1) selling cores for reuse, (2) selling intermediates or components for reuse, and (3) selling elements for recycling. Here, the second and third profits are potential revenues that might be obtained by keeping elements in storage for future use. Therefore, they are calculated based on expected values and are considered as parameters in this study.

The rest of this paper is organized as follows. Section 2 reviews the related literature on the reassembly process planning, inventory control policies, and the part value depreciation. Section 3 describes the ILP model based on a network flow graph and Section 4 shows an illustrative example of a smartphone. Lastly, Section 5 summarizes the findings and concludes the study.

\section{Literature Review}

\subsection{Assembly, Disassembly, and Reassembly in Order based Systems}

The number of studies addressing the reassembly planning in remanufacturing systems is very limited [11]. This is due to the fact that reassembly is often considered to be identical to the conventional assembly in manufacturing systems and therefore traditional assembly-based methodologies such as line-balancing are adopted to facilitate the reassembly planning [6]. However, there are fundamental differences between assembly and reassembly as summarized in Table 1 [7]. First, assembly is a manufacturing process for the value creation, while reassembly is a remanufacturing process for the value recovery. Second, often the outputs of assembly processes are complete assemblies considered as final products, while the outputs of reassembly processes can be complete or incomplete assemblies. Reassembly costs are usually higher than assembly costs, since reassembly is 
a labor intensive process. Additionally, the input parts to reassembly processes often have uncertain quality levels, where upgrades or part substitutions are needed.

Most of the previous studies in the ATO-based remanufacturing addressing reassembly have highlighted the part substitution issue [1], [4], [12]. To name a few, Jin et al. (2011) suggested an optimal policy for the product reassembly with the part substitution considering the uncertainty in the quality of incoming products to a remanufacturing system [4]. Mashhadi et al. (2015) also proposed an optimization model to determine the best upgrade level under the uncertain demand and the high variability in the quality of incoming supply [12]. The substitution of parts can be conducted at a product family as well as the product model. As it allows components to be shared among different product models, the product family concept has been well recognized as an effective way to increase the manufacturing productivity in terms of enhancing the flexibility of production processes, reducing the development complexity, and improving the ability to upgrade [13]. Park and Kremer (2015) studied the impact of design and manufacturing complexity in a product family on the manufacturing performance [14]. In this paper, however, we assume that unqualified elements are already sorted and removed before the reassembly. Therefore, the decision-making in this study will be conducted on qualified elements that do not require any replacement. Furthermore, the concept of product family is not covered in here. We consider an ATO system where a single product model includes one core, multiple intermediates, and components.

Disassembly is another similar concept to reassembly (as summarized in Table 1) that has been covered in numerous remanufacturing-related studies including scheduling, sequencing, line-balancing, and disassemble-toorder (DTO) systems [6]. In demand-driven remanufacturing systems, DTO problems are concerned with determining the best combination of multiple products that selectively should be disassembled to satisfy the market demand [15]. Kongar and Gupta (2006) proposed a DTO system where used products are disassembled for the retrieval of reusable components [16]. They used the fuzzy goal programming technique to solve a multicriteria problem under uncertainty. In another study, they solved a DTO problem using a linear physical programming [17]. Gupta et al. (2010) dealt with the same problem using a neural network (NN) technique [18]. 


\subsection{Production and Inventory Control Planning in ATO Systems}

The current ATO systems use a different manufacturing planning method than the material requirement planning (MRP) and inventory control techniques. For a product having a hierarchical structure, first the master production scheduling (MPS) is completed based on the future demand predicted for certain periods. As the top-down deployment using the bill-of-material (BOM) explosion, the MRP is scheduled based on the exact amount and timing of assembly for each component. In other words, the traditional production planning is based on the wellpredicted future demand. However, remanufacturing systems deal with high degrees of uncertainty in timing and quantity of demand as well as process time and yield [19], [20]. Therefore, different research methods have been developed in the remanufacturing production planning to address these uncertainties. Souza and Ketzenberg (2002) proposed a MPS method based on the queueing theory to solve the resource utilization problem in maketo-order remanufacturing systems [21]. DePuy et al. (2007) developed a probabilistic form of standard MRP to estimate the number of remanufactured products available to meet the market demand considering the variable yield rates of incoming supplies with uncertain quality grades [22]. Souza (2010) developed an MRP-based production planning method where a measurement factor was suggested to forecast the uncertainty of incoming products [23]. 
Optimization methods and mathematical programming techniques have also been commonly used in the production planning for assembly. To name a few, Pochet (2006) solved an assembly-based production planning problem employing a mixed integer programing (MIP) [24]. Jayaraman (2006) suggested a linear programming model called Remanufacturing Aggregate Production Planning (RAPP) [25]. Xanthopoulos and Iakovou (2009) proposed a mixed-integer linear programming (MILP) model to determine the number of used products that should be collected, disassembled, remanufactured, and disposed of in each period [26]. However, most of the previous studies have been focused on satisfying the demand for final products without considering demands for sub-assemblies. As mentioned in Table 1, sub-assemblies such as intermediates and components can be extracted from incomplete assemblies, and traded for each market. Therefore, the current study addresses the demand for both end-products and subassemblies.

In addition to production planning, inventory control planning has also been the point of attention in the previous ATO studies [27]-[29]. To list a few studies, Benjaafar and ElHafsi (2006) proposed an inventory control policy based on markov decision processes for an ATO system with multiple customer classes [30]. ElHafsi (2009) extended the previous study to the case of the Coordinated Based-stock with Rationing and Compound Demands (CBRCD) policy [31]. Keblis and Feng (2012) suggested an optimal inventory control policy to maximize the total discounted profit through controlling the component production [32]. Gunter (2004) developed the first inventory model for remanufactured parts [6], [33]. He transferred the logic of economic order quantity (EOQ) model into remanufacturing systems considering multiple components. Bazan et al. (2016) recently provided a review of inventory control studies in the reverse logistics domain [34].

To sum up, what distinguishes the current work from the previous studies is a decision-making model that simultaneously determines both reassembly and procurement plans, while considering the market demand for both cores and subassemblies. In addition, the concept of part depreciation value and the disposal point have been included in our analyses with the aim of considering the product technological obsolescence fact, as an important factor in remanufacturing systems. 


\subsection{Depreciation of Part Value}

The depreciation of part value is a critical issue that reflects the technological obsolescence of products over time. Considering the concept of part's depreciation value, many studies have been conducted on perishable goods such as food, blood, drugs, and photographic films, where the product value decreases over time [35]-[37]. For consumer electronics, an exponential decay function is usually adopted to represent the part value over its lifetime. For example, Guide (2006) assumed an exponential price decay model for both primary and secondary markets [38]. Kwak (2012) conducted an empirical analysis and established several regression models to determine the product value for several categories of consumer electronics such as laptops and cellphones considering product specifications, conditions, and age [39]. However, the regression models can only be used for certain products due to the lack of generalization.

In the current study, a monotonously decreasing function similar to an exponential decay model is adopted to model the part depreciation. Additionally, this study assumes that the part value in the primary market is identical to its buy-back price in the secondary market.

\section{A Graph-based Integer Linear Programming Model for Reassembly Planning}

\subsection{Network Flow Model}

In this section, a network flow model based on a directed arc graph (DAG) is introduced to represent the planning problem. Table 2 summarizes the notations being used in this network model. A DAG is symbolized by graph G consisting of a node set $\mathrm{N}$ and an arc set $\mathrm{A}$. $\mathrm{N}$ consists of four types of nodes: element nodes $\mathrm{E}$, reassembly process nodes R, source nodes S, and sink nodes K. E involves three types of elements (core, intermediate and component). $\mathrm{S}$ includes two source nodes: the inventory (initial state) and the procurement denoted by $\alpha$ and $\beta$, each representing a different origin for element flows. Therefore, flows coming from Source Node $\alpha$ or $\beta$ indicate taking out elements from stock or buying elements from suppliers. $K$ also involves two sink nodes: inventory (keeping) and demand denoted by $\psi$ and $\omega$ representing the fate of element flows. Hence, flows going to Sink Nodes $\psi$ or $\omega$ signify keeping elements to stock or satisfying a demand for a core. For any arc $(u, v)$ of $A$ in graph 

used in the network flow model: $T N(u)$ and $H N(u)$. The former is a set of tail nodes of the arcs incident to Node $u$, while the latter is a set of head nodes of the arcs incident from Node $u$ [40].

A DAG $G$ is separated into three layers according to the node types. Figure 2 illustrates an example of a network model corresponding to the element structure shown in Figure 1-(a). Layer 1 and Layer 3 are for source and sink nodes respectively. Element nodes and reassembly process nodes are included in Layer 2. Element nodes can be specifically distinguished by core, intermediate and component nodes. In Figure 2, component nodes are Nodes 3 , 4, 5 and 6 , intermediate nodes are Nodes 1 and 2 , and a core node is a Node $\theta$. Nodes $\hat{1}, \hat{2}$ and $\hat{\theta}$ denote reassembly process nodes to make Intermediates 1 and 2 , and Core $\theta$, respectively. In this graph, a reassembly process node is only represented by a triangular shape to be recognized well.

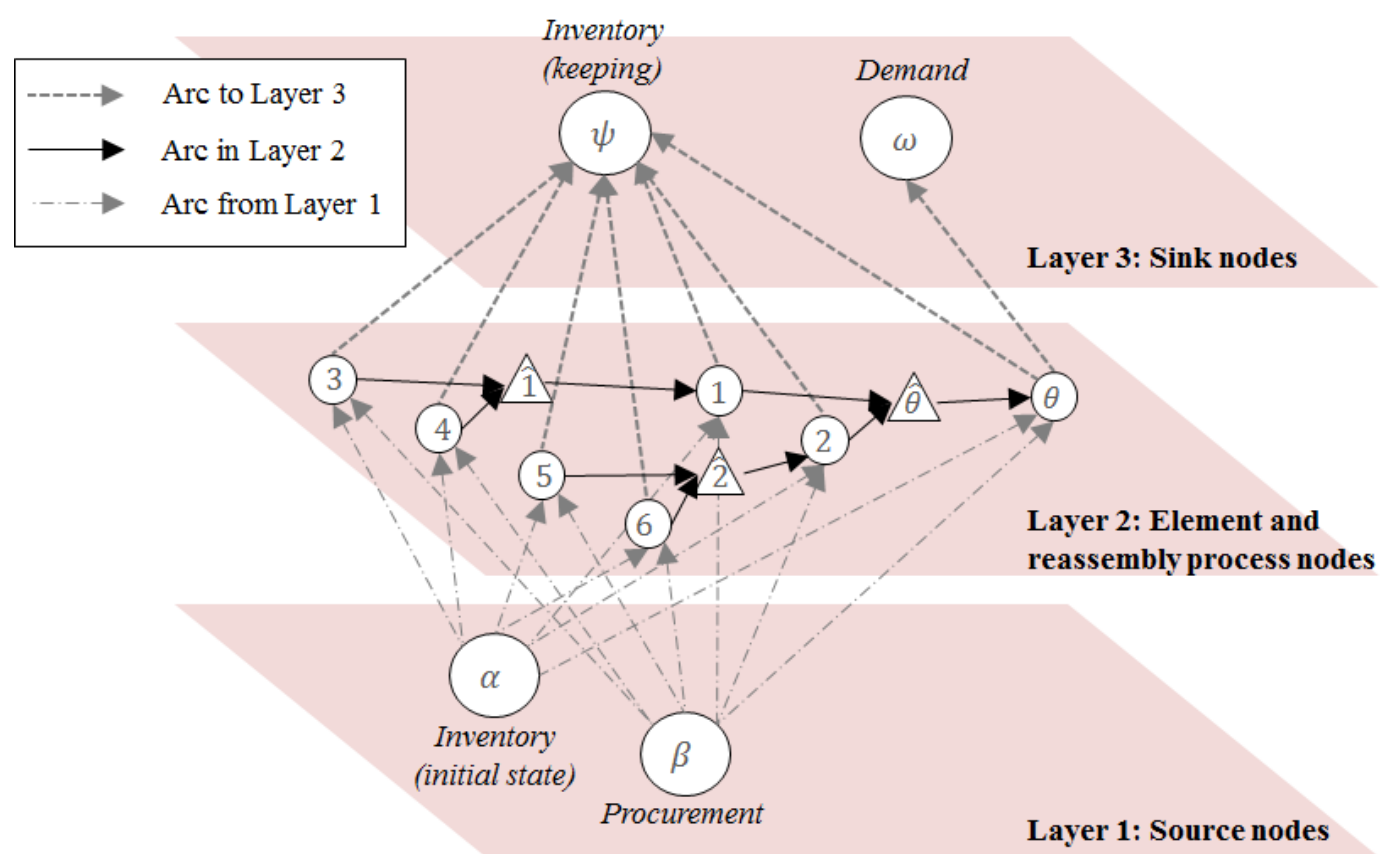

Figure 2. An example of the network flow model

Table 2. Network flow notation 


\subsection{Objective Function}

Equation (1) shows the objective function consisted of two revenue parts and two cost parts: certain revenue from selling cores $\left(R_{1}\right)$, expected revenue from keeping elements to stock $\left(R_{2}\right)$, reassembly process cost to make intermediates and cores $\left(C_{1}\right)$, and procurement cost to buy elements $\left(C_{2}\right)$. The objective function has four decision variables: $x_{\beta i}, x_{i i}, x_{i \psi}$, and $x_{\theta \omega}$. Table 3 provides the specific explanation of mathematical notations used in ILP. Note that fixed or setup costs of reassembly operations for batch items are not considered to simplify the model.

$i$ is an index for element nodes that consists of component, intermediate and core nodes. In addition, $\hat{\imath}$ is an index for reassembly process nodes, namely, it means a reassembly process to make an element $i$. Therefore, component $i$ does not have a reassembly process $\hat{\imath}$ because components are atomic parts not being reassembled. In this study, the value depreciation of element $i$ over time $t$ is represented by a monotonously decreasing function $\gamma_{i}(t)$. Thus, $\gamma_{\theta}(0)$ indicates the current market value of $\operatorname{Core} \theta(t=0) . \Delta_{i}$ is the expected unit revenue of keeping element $i$, and Section 3.4 elucidates how to attain this parameter. $\sigma_{i}$ indicates a procurement unit cost for element $i$, and is larger than $\gamma_{i}(0)$ since it includes a purchasing cost as well as a procurement processing cost such as a delivery cost. $\rho_{i}$ denotes the reassembly unit cost of making element $i$. 
Where $R_{1}=x_{\theta \omega} \gamma_{\theta}(0) ; R_{2}=\sum_{i \in E} x_{i \psi} \Delta_{i} ; C_{1}=\sum_{i \in E, \hat{\imath} \in R} x_{\hat{\imath} i} \rho_{i} ;$ and $C_{2}=\sum_{i \in E} x_{\beta i} \sigma_{i}$

In this study, two calculation phases are conducted to obtain the optimal solution of a reassembly-to-order planning. The first phase is to obtain the potential revenue of keeping each element $i, \Delta_{i}$. The next phase is to find the optimal number of reassembly and procurement using the ILP model. As a parameter, $\Delta_{i}$ coming from the first phase is used to the objective function of the ILP model.

Table 3. Mathematical notation for integer linear programming

\begin{tabular}{ll}
\hline Notation & Description \\
\hline Index & \\
\hline$i$ & Index for element (component, intermediate and core) nodes; $i \in E$ \\
\hline$\hat{\imath}$ & Index for reassembly process nodes; $\hat{\imath} \in R$ \\
\hline$s$ & Index for source nodes; $s \in S$ \\
\hline$k$ & Index for sink nodes; $k \in K$ \\
\hline Decision variable & \\
\hline$x_{\beta i}$ & Flow through arc $(\beta, i)$, the number of element $i$ to procure from suppliers \\
\hline$x_{\hat{\imath} i}$ & Flow through arc $(\hat{\imath}, i)$, the number of reassembled element $i$ from reassembly process $\hat{\imath}$ \\
\hline$x_{\theta \omega}$ & Flow through arc $(\theta, \omega)$, the number of core $\theta$ to satisfy a demand quantity \\
\hline$x_{i \psi}$ & Flow through arc $(i, \psi)$, the number of element $i$ for keeping \\
\hline$P a r a m e t e r$ & \\
\hline$x_{\alpha i}$ & Flow through arc $(\alpha, i)$, the initial number of element $i$ stored in the inventory \\
\hline$D$ & Demand quantity for a core \\
\hline$\sigma_{i}$ & Procurement unit cost for element $i ; \sigma_{i}>\gamma_{i}(0)$ \\
\hline$\rho_{i}$ & Reassembly unit cost to make element $i$ \\
\hline$\gamma_{i}(0)$ & Current market value of element $i$ \\
\hline$L_{i}$ & Upper limit for the procurement number of element $i$ \\
\hline$z_{i \hat{\imath}}$ & Number of necessary units of element $i$ to reassemble element $i^{\prime} ; z_{i \imath^{\prime}}>0$ and integer \\
\hline$\Delta_{i}$ & Expected revenue of keeping element $i$ \\
\hline$\tau_{i}$ & Disposal point of element $i$ \\
\hline$h_{i}$ & Unit holding cost of element $i$ \\
\hline$\mu_{i}$ & Disposal value of element $i$ \\
\hline$r_{i}$ & Recycling benefit of element $i$ \\
\hline$c_{i}$ & Disposal cost of element $i$ \\
\hline$\lambda_{i}$ & Average arrival rate of the demand for element $i$ \\
\hline$\rho_{i}^{*}$ & Reassembly threshold reassembling into element $i$ \\
\hline$p_{i}$ & Reassembly unit profit reassembling into element $i$ \\
\hline
\end{tabular}




\subsection{Constraints}

\section{Flow balance for element nodes}

The flow balance is considered as a constraint in the network flow model for all element nodes, where the sum of incoming flows to a node should be equal to the sum of outgoing flows. Figure 3 represents incoming and outgoing arcs for each element node $i$ that can be a component, intermediate or core node. In common, all element nodes have incoming arcs from inventory (initial state) $\alpha$ and procurement $\beta$, and an outgoing arc to inventory (keeping) $\psi$. However, intermediate and core nodes only have one more incoming arc coming from reassembly process node $\hat{\imath}$ to reflect the point that components are atomic parts that cannot be disassembled further. Component and intermediate nodes also have only one outgoing arc to reassembly process node $\widehat{l}^{\prime}$ to make another element $i^{\prime}$ since a core is an end-item to be reassembled. Additionally, a core node only has one outgoing arc into Demand Node $\omega$ to represent selling cores to the market. For the intermediate node in Figure 3-(b), intermediate $i$ can be generated by reassembly process $\hat{\imath}$, and the intermediate $i$ can also be used to make intermediate or core $i^{\prime}$ through reassembly process $\widehat{\imath^{\prime}}$. Equation (2) presents flow balance for element $i$. In the equation, the left side is the sum of incoming flows while the right side is the sum of outgoing flows.

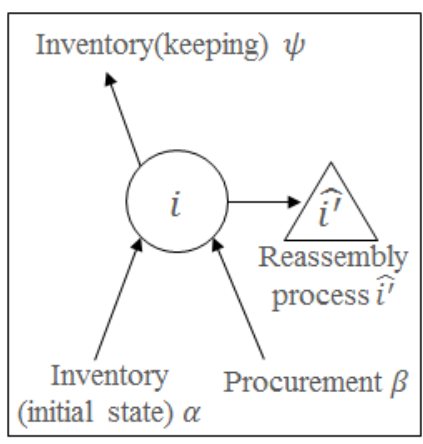

(a) Component

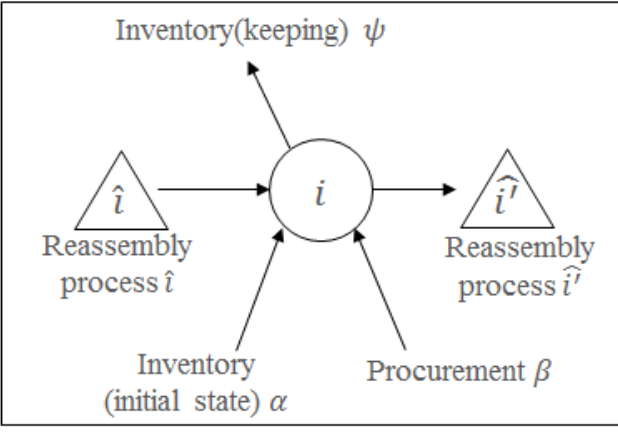

(b) Intermediate

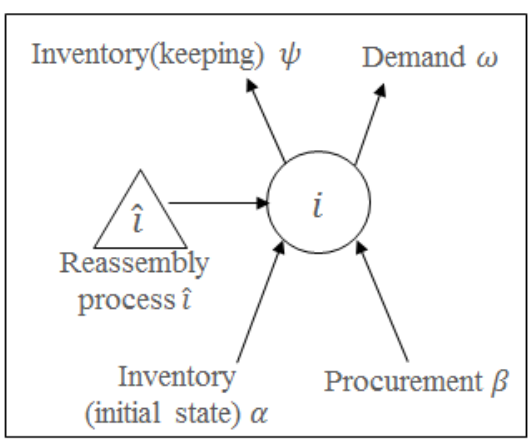

(c) Core

Figure 3. Incoming and outgoing arcs based on an element node: (a) component; (b) intermediate; or (c) core

$$
\sum_{u \in T N(i)} x_{u i}=\sum_{v \in H N(i)} x_{i v}, \quad \forall i \in E
$$




\section{Flow balance for reassembly process nodes}

Unlike element nodes, incoming and outgoing flows of reassembly process nodes are basically unbalanced. This is because plural elements are integrated to form another element during a reassembly process. This is represented as the flow merging in networks. As shown in Figure 4, Huang (2011) defined an assembly model in the network flow problems [41]. Equation (3) comes from his assembly equation, where the number of reassembled parent elements is identical to the input number of each child element. Herein, the input number means the number of child elements to join reassembly. The equation consists of the flow going to parent element node $i^{\prime}, x_{\hat{\imath}^{\prime} i^{\prime}}$, the flow coming from each child element $i, x_{i \imath^{\prime}}$, and the number of necessary units of each element $i$ for reassembly to make the parent element $i^{\prime}, z_{i \imath^{\prime}}$. Using this equation, incoming flows from child elements can be merged into an outgoing flow to form a parent element.

$$
x_{\widehat{\imath^{\prime}} i^{\prime}}=\frac{x_{i \widehat{l}^{\prime}}}{z_{i \widehat{\imath}^{\prime}}}, \quad \forall i, i^{\prime} \in E, \forall \widehat{\imath^{\prime}} \in R
$$

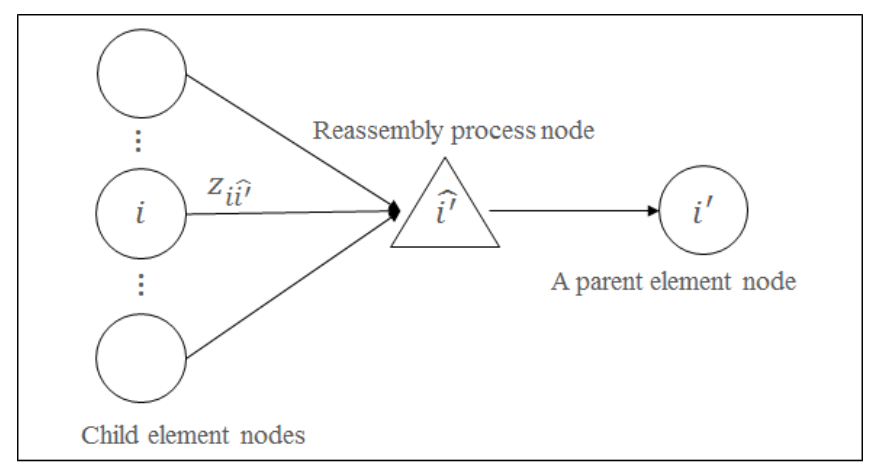

Figure 4. A reassembly process node in the network flow model for assembly (modified from [41])

\section{Absolute and flexible demands}

The imbalance between returns of used products and the demand for cores is a critical issue in remanufacturing systems [42]. In practice, this could result in the lack of elements for reassembly to satisfy a demand, since the amount of used products supply is often uncertain. In this case, remanufacturers procure elements to fulfill the lack of elements in order to satisfy the demand. To reflect this situation, two cases for demand, $D$ are considered: 
absolute and flexible demands. Absolute demand is the case in which the remanufacturer has to satisfy the exact demand quantity, whereas in the flexible demand case an upper bound is provided. Equations (4) and (5) represent these two cases. $x_{\theta \omega}$ refers to the flow entering Demand Node $\omega$, which means the number of Core $\theta$ to satisfy $D$. In the ILP model, only one of the constraints is used depending on the situation.

$$
\begin{aligned}
& x_{\theta \omega}=D \\
& x_{\theta \omega} \leq D
\end{aligned}
$$

\section{Procurement limit}

Equation (6) shows an upper bound for the number of elements procured from suppliers. $x_{\beta i}$ is the flow coming from Procurement Node $\beta$ as one of the source nodes and $L_{i}$ is the upper limit for procurement of element $i$.

$$
x_{\beta i} \leq L_{i}, \quad \forall i \in E
$$

\section{Decision variables condition}

Lastly, all decision variables should be non-negativity and integer, since flows represent the quantity.

$$
x_{u v} \geq 0 \text { and integer }, \quad \forall u, v \in N
$$

\subsection{Expected Revenue of Storing Elements}

In the proposed model, remanufacturers decide whether elements are reassembled or not. If elements are not reassembled, remanufacturers would store them in the inventory and wait for selling out to customers or recyclers in the future. This section describes how the expected revenue of storing elements, $\Delta_{i}$, is computed. To obtain $\Delta_{i}$, it is assumed that the inter-arrival time of customer orders is exponentially distributed with $\lambda_{i}$, a demand arrival rate of element $i$. Note that a demand arrival rate for each element, $\lambda_{i}$, is different from the number of certain demand for final products $(D)$. The holding cost and the market value vary for each element. Moreover, the 
market value of element $i$ is changed according to a monotonously decreasing function over time, $\gamma_{i}(t)$ to represent the value depreciation.

\section{Disposal value}

When elements are disposed of, remanufacturers consider the recycling benefit and the disposal cost. Herein, the recycling benefit represents selling benefits of elements to recyclers, and the disposal cost reflects the processing cost to remove elements such as incinerate cost or landfill cost if elements cannot be sold out to recyclers. Therefore, the disposal value will be positive or negative depending on end-of-life (EOL) options. In Equation (8), $\mu_{i}$ is disposal value, and $r_{i}$ and $c_{i}$ are recycling revenue and disposal cost for element $i$. Remanufacturers can dispose of elements whenever they want meaning that they are able to obtain profit or loss from $\mu_{i}$ at anytime.

$$
\mu_{i}=r_{i}-c_{i}, \quad \forall i \in E
$$

\section{Disposal point}

The dashed line in Figure 5 is the net-profit calculated by the difference between the market value $\gamma_{i}(t)$, namely selling benefit, and a cumulated holding cost of element $i$ denoted by $h_{i} t$. In the example shown in Figure 5, the remanufacturer already has a guaranteed revenue as the disposal value $\mu_{i}$ since they are able to obtain this revenue anytime. Therefore, the remanufacturer sells element $i$ to meet the market demand as long as the net-profit is higher than the guaranteed revenue $\mu_{i}$. However, if the element is not sold out until time $\tau$, the remanufacture would dispose of the element as soon as possible to avoid holding costs. In this case, the disposal point $\tau_{i}$ is the intersection point of the net-profit curve and the disposal value $\mu_{i}$, and is obtained by solving Equation (9). We use a software to find $\tau_{i}$ in Section 4 . When disposal value $\mu_{i}$ is negative, the same equation is applied as well since the remanufacturer would wait for selling element $i$ for a demand until the disposal point $\tau$ to minimize the guaranteed loss $\mu_{i}$. 


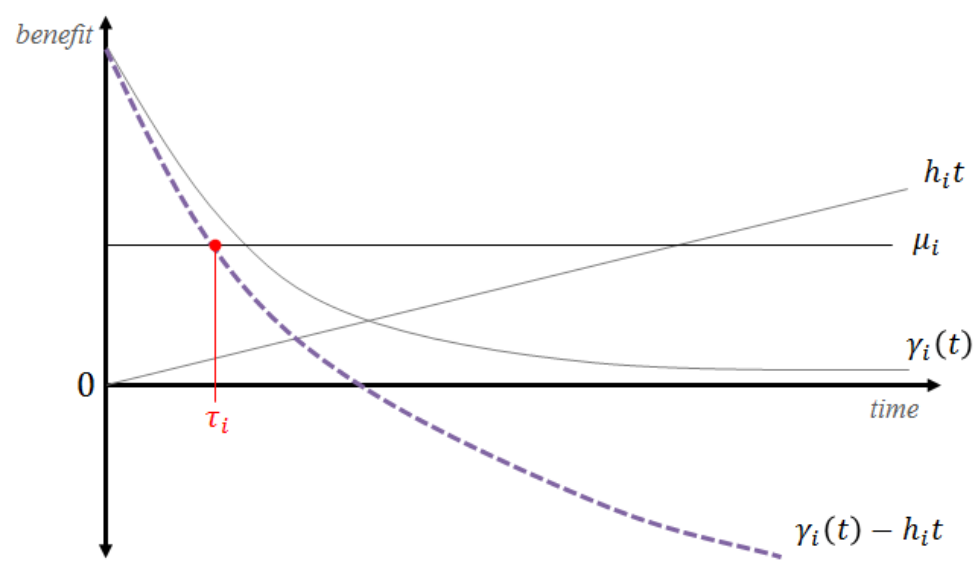

Figure 5. Disposal point

$$
\mu_{i}=\gamma_{i}\left(\tau_{i}\right)-h_{i} \tau_{i}
$$

\section{Expected value of future demands}

The inter-arrival time of customer orders is exponentially distributed with $\lambda_{i}$. The probability density function is shown in Equation (10), and the expected value of the profit function is shown in Equation (11) [43]. Here, the function $g_{i}(t)$ is the remanufacturer's benefit or cost over time as explained in Figure 5. A decision on whether to wait or dispose of elements depends on the disposal point $\tau_{i}$. Therefore, the equation is separated into two parts as shown in Equation (12), and elaborated in Equations (13) and (14).

$$
\begin{gathered}
f_{i}(t)=\lambda_{i} e^{-\lambda_{i} t} \\
E\left[g_{i}(t)\right]=\int_{0}^{\infty} g_{i}(t) f_{i}(t) d t \\
g_{i}(t)=\left\{\begin{array}{c}
\gamma_{i}(t)-h_{i} t, \quad \text { if } t \leq \tau_{i} \\
\mu_{i}, \quad \text { otherwise }
\end{array}\right. \\
E\left[g_{i}(t)\right]=\int_{0}^{\tau_{i}} g_{i}(t) f_{i}(t) d t+\int_{\tau_{i}}^{\infty} g_{i}(t) f_{i}(t) d t \\
\Delta_{i}=E\left[g_{i}(t)\right]=\int_{0}^{\tau_{i}}\left(\gamma_{i}(t)-h_{i} t\right)\left(\lambda_{i} e^{-\lambda_{i} t}\right) d t+\int_{\tau_{i}}^{\infty}\left(\mu_{i}\right)\left(\lambda_{i} e^{-\lambda_{i} t}\right) d t
\end{gathered}
$$




\subsection{Reassembly Threshold}

Fundamentally, elements are reassembled as long as a reassembly process is profitable. In other words, elements would be kept in stock rather than reassembled if reassembly cost is high. Reassembly threshold is a tipping point of reassembly unit cost, where it defines whether elements are going to the inventory or reassembly. Reassembly threshold for element $i, \rho_{i}^{*}$, can be obtained by Equation (15) where $\rho_{i}^{*}$ is the difference between the parent element's revenue and its child elements' potential revenue. The potential revenue of the child elements actually indicates the opportunity cost occurred by reassembly. For $i=\theta$, the parent's revenue is current market value $\gamma_{\theta}(0)$ since it can be generated by the current demand. Equation (16) shows the unit profit, $p_{i}$, generated when reassembly is conducted once. Consequently, a reassembly process for making element $i$ is conducted when $p_{i}$ is positive.

$$
\begin{gathered}
X_{i}-\sum_{j \in T N(\hat{\imath})} \Delta_{j}=\rho_{i}^{*}, \quad\left\{\begin{array}{l}
\text { if } i=\theta, X_{i}=\gamma_{i}(0) \\
\text { otherwise, } X_{i}=\Delta_{i}
\end{array}, \forall i \in E, \forall \hat{\imath} \in R\right. \\
p_{i}=\rho_{i}^{*}-\rho_{i}, \quad \forall i \in E
\end{gathered}
$$

However, even though $p_{i}$ is negative, the reassembly can be conducted only if the revenue of element $i$ 's ancestors cover its loss. For instance, suppose that $\gamma_{\theta}(0)$ is a huge positive number, and $p_{1}$ and $p_{2}$ are small negative numbers in Figure 2. Making the intermediates with the components, the reassembly processes can be conducted due to the fact that the large revenue from satisfying a demand for a core can compensate the minor losses of descendant elements.

\section{Illustrative Example: Smartphone}

\subsection{Smartphone Elements}

Figure 6 displays the hierarchical relationships among different elements of a smartphone. The smartphone structure and assembly information are obtained from ifixit.com. The smartphone has 1 core, 3 intermediates, and 18 components. Table 5 provides the model inputs including the number of necessary units for a reassembly $z_{i i^{\prime}}$, recycling benefit $r_{i}$, disposal cost $c_{i}$, disposal value $\mu_{i}$, and holding unit cost $h_{i}$. All reassembly processes require 

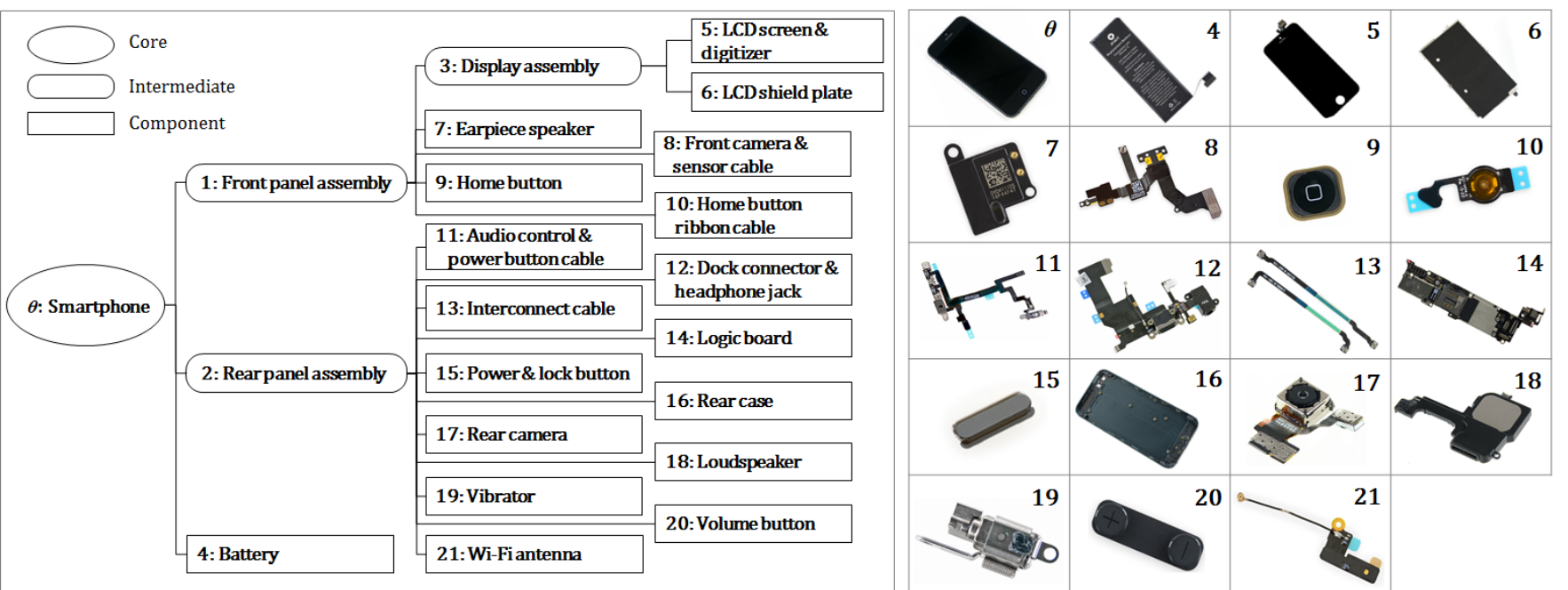

Figure 6. Smartphone structure (information was extracted from iFixit.com)

only one unit for each input element to make a reassembled element, meaning that $z_{i i^{\prime}}$ is 1 for $\forall i \in E /\{\theta\}$. It is assumed that $r_{i}$ and $c_{i}$ of a parent element is the sum of child elements' recycling benefit and disposal cost, respectively. For instance, Core $\theta$ 's recycling benefit, $\$ 1$, is the sum of recycling benefits of Intermediates 1 and 2 , and Component 4, all of which are the core's child elements. Disposal value $\mu_{i}$ is calculated with $r_{i}$ and $c_{i}$ based on Equation (8). As $r_{i}$ and $c_{i}$ are parameters, $\mu_{i}$ is also constant over time. Since the remanufacturers can dispose of elements whenever they want, they are able to obtain the constant revenue $\mu_{i}$ as the disposal of element $i$ regardless of time. For holding unit costs, $\$ 1, \$ 0.5$, and $\$ 0.1$ are assigned to the core, intermediates and components. The initial inventory for element $i$ is represented by flow $x_{\alpha i}$ coming from Inventory Node (Initial State) $\alpha$. The components have 20 units as their initial inventory in this example. 


\begin{tabular}{|c|c|c|c|c|c|c|c|}
\hline $\begin{array}{l}\text { Node } \\
: i\end{array}$ & Element name & Type & $\begin{array}{l}\text { \# of units } \\
\text { for an } \\
\text { assembly } \\
\text { (units): } z_{i \widehat{\imath} \hat{\imath}^{\prime}}\end{array}$ & $\begin{array}{l}\text { Recycling } \\
\text { benefit } \\
(\$): r_{i}\end{array}$ & $\begin{array}{l}\text { Disposa } \\
1 \text { cost } \\
(\$): c_{i}\end{array}$ & $\begin{array}{l}\text { Disposal } \\
\text { value }(\$) \text { : } \\
\mu_{i}\end{array}$ & $\begin{array}{l}\text { Holding } \\
\text { unit cost } \\
\text { (\$/month } \\
\text { /unit): } h_{i}\end{array}$ \\
\hline$\theta$ & Smartphone & Core & 0 & 1.00 & 0.73 & 0.27 & 1.00 \\
\hline 1 & Front panel assembly & Intermediate & 1 & 0.48 & 0.24 & 0.24 & 0.50 \\
\hline 2 & Rear panel assembly & Intermediate & 1 & 0.38 & 0.19 & 0.19 & 0.50 \\
\hline 3 & Display assembly & Intermediate & 1 & 0.40 & 0.20 & 0.20 & 0.50 \\
\hline 4 & Battery & Component & 1 & 0.14 & 0.30 & -0.16 & 0.10 \\
\hline 5 & LCD screen \& digitizer & Component & 1 & 0.20 & 0.10 & 0.10 & 0.10 \\
\hline 6 & LCD shield plate & Component & 1 & 0.20 & 0.10 & 0.10 & 0.10 \\
\hline 7 & Earpiece speaker & Component & 1 & 0.02 & 0.01 & 0.01 & 0.10 \\
\hline 8 & Front camera \& sensor cable & Component & 1 & 0.02 & 0.01 & 0.01 & 0.10 \\
\hline 9 & Home button & Component & 1 & 0.02 & 0.01 & 0.01 & 0.10 \\
\hline 10 & Home button ribbon cable & Component & 1 & 0.02 & 0.01 & 0.01 & 0.10 \\
\hline 11 & Audio control \& power button cable & Component & 1 & 0.02 & 0.01 & 0.01 & 0.10 \\
\hline 12 & Dock connector \& headphone jack & Component & 1 & 0.02 & 0.01 & 0.01 & 0.10 \\
\hline 13 & Interconnect cable & Component & 1 & 0.02 & 0.01 & 0.01 & 0.10 \\
\hline 14 & Logic board & Component & 1 & 0.10 & 0.05 & 0.05 & 0.10 \\
\hline 15 & Power \& lock button & Component & 1 & 0.02 & 0.01 & 0.01 & 0.10 \\
\hline 16 & Rear case & Component & 1 & 0.10 & 0.05 & 0.05 & 0.10 \\
\hline 17 & Rear camera & Component & 1 & 0.02 & 0.01 & 0.01 & 0.10 \\
\hline 18 & Loudspeaker & Component & 1 & 0.02 & 0.01 & 0.01 & 0.10 \\
\hline 19 & Vibrator & Component & 1 & 0.02 & 0.01 & 0.01 & 0.10 \\
\hline 20 & Volume button & Component & 1 & 0.02 & 0.01 & 0.01 & 0.10 \\
\hline 21 & Wi-Fi antenna & Component & 1 & 0.02 & 0.01 & 0.01 & 0.10 \\
\hline
\end{tabular}

\subsection{Scenarios in ATO-based Remanufacturing Systems}

In this section, eight scenarios from a combination of six cases are addressed (Table 5). Three pairs of two contrasting cases are considered to show several dissimilar situations. Cases 1 and 2 represent the cases of a relatively latest product and an obsolete product respectively. Cases 3 and 4 represent the case of absolute and flexible demand, and Cases 5 and 6 show the manual and automated reassembly processes. Consequently, the ILP model was run for eight different scenarios made by a combination of these six cases.

Table 5. Eight scenarios from the combination of six cases

\begin{tabular}{l|l|l|l|l}
\hline & \multicolumn{2}{|l|}{ Case 3: Absolute demand (A) } & \multicolumn{2}{l}{ Case 4: Flexible demand (F) } \\
\cline { 2 - 5 } & $\begin{array}{l}\text { Case 5: Manual } \\
\text { reassembly process (M) }\end{array}$ & $\begin{array}{l}\text { Case 6: Automated } \\
\text { reassembly process (A) }\end{array}$ & $\begin{array}{l}\text { Case 5: Manual } \\
\text { reassembly process (M) }\end{array}$ & $\begin{array}{l}\text { Case 6: Automated } \\
\text { reassembly process (A) }\end{array}$ \\
\hline $\begin{array}{l}\text { Case 1: Latest } \\
\text { product (L) }\end{array}$ & Scenario 1: L.A.M. & Scenario 2: L.A.A. & Scenario 3: L.F.M. & Scenario 4: L.F.A. \\
\hline $\begin{array}{l}\text { Case 2: Obsolete } \\
\text { product (O) }\end{array}$ & Scenario 5: O.A.M. & Scenario 6: O.A.A. & Scenario 7: O.F.M. & Scenario 8: O.F.A. \\
\hline
\end{tabular}


Table 6 shows a parameter comparison between the latest product case (Case 1) and the obsolete product case (Case 2). In this example, the latest product is a smartphone model with the launch time of less than a half year, while the obsolete product is launched over three years ago. The table represents that Case 1 has higher current market value for all elements in comparison with Case 2. The actual market values of elements have been obtained from online retailers (e.g. amazon.com and ifixit.com). The current market value for each element, $\gamma_{i}(0)$, is the average of minimum and maximum market prices.

In reality, the market trades for some intermediates are limited. In this example, it is assumed that these intermediates have no market; therefore, several parameter values are assumed without calculation. For instance, Nodes 1 and 2 represent the front panel assembly and the rear panel assembly. They have zero market value $\gamma_{i}(0)$, the demand arrival rate $\lambda_{i}$ and the expected value of storing $\Delta_{i}$. A big number is considered for the procurement $\operatorname{cost} \sigma_{i}$ to restrain from procuring those elements. Additionally, procurement unit cost $\sigma_{i}$ has $\$ 30$ more than $\gamma_{i}(0)$ for element $i$ because it may include procurement processing costs such as a setup cost and a delivery cost as well as $\gamma_{i}(0)$ as a purchasing cost. In this example, an exponential distribution shown in Equation (16) is used for the part depreciation model. $\gamma_{i}(t)$ is the value of element $i$ at time $t$, meaning that $\gamma_{i}(0)$ is the current market value of element $i$. For this equation, all elements have a common depreciation parameter $a_{i}$ of 0.036 . The estimated number is obtained from the market value trends captured from camelcamelcamel.com. Applying Equations (16) and (14), Equation (17) represents the expected value of storing element $i$.

$$
\begin{gathered}
\gamma_{i}(t)=\gamma_{i}(0) e^{-a_{i} t} \\
\Delta_{i}=\frac{\gamma_{i}(0) \lambda_{i}}{a_{i}+\lambda_{i}}\left(1-e^{-\left(a_{i}+\lambda_{i}\right) \tau_{i}}\right)+e^{-\lambda_{i} \tau_{i}}\left(h_{i} \tau_{i}+\frac{h_{i}}{\lambda_{i}}+\mu_{i}\right)-\frac{h_{i}}{\lambda_{i}}
\end{gathered}
$$

Excel's Goal Seek is used to find the disposal point $\tau_{i}$ based on Equation (9). The latest model case has the frequent demand arrival rate of 10 units per month. In addition, the latest model has a higher potential value of storing, $\Delta_{i}$, based on Equation (16). The more frequent the demand arrival rate is, the higher the chance to sell an element in the future is, which means that remanufacturers can expect high revenues for the element afterward, even if the element is stored now and not sent for disposal or recycling. 
Table 6. Parameter values used in Cases 1 and 2

\begin{tabular}{|c|c|c|c|c|c|c|c|c|c|c|}
\hline \multirow{2}{*}{$\begin{array}{l}\text { Node } \\
: i\end{array}$} & \multicolumn{5}{|c|}{ Case 1: Latest product (L) } & \multicolumn{5}{|c|}{ Case 2: Obsolete product $(\mathrm{O})$} \\
\hline & $\begin{array}{l}\text { Current } \\
\text { market } \\
\text { value }(\$) \text { : } \\
\gamma_{i}(0)\end{array}$ & $\begin{array}{l}\text { Procure- } \\
\text { ment unit } \\
\text { cost } \\
\text { (\$/unit): } \\
\sigma_{i}\end{array}$ & $\begin{array}{l}\text { Disposal } \\
\text { point } \\
\text { (month): } \\
\tau_{i}\end{array}$ & $\begin{array}{l}\text { Demand } \\
\text { arrival } \\
\text { rate (units } \\
\text { /month): } \\
\lambda_{i}\end{array}$ & $\begin{array}{l}\text { Expected } \\
\text { value of } \\
\text { storing } \\
(\$): \Delta_{i}\end{array}$ & $\begin{array}{l}\text { Current } \\
\text { market } \\
\text { value }(\$) \text { : } \\
\gamma_{i}(0)\end{array}$ & $\begin{array}{l}\text { Procure- } \\
\text { ment unit } \\
\text { cost } \\
\text { (\$/unit): } \\
\sigma_{i}\end{array}$ & $\begin{array}{l}\text { Disposal } \\
\text { point } \\
\text { (month): } \\
\tau_{i}\end{array}$ & $\begin{array}{l}\text { Demand } \\
\text { arrival } \\
\text { rate (units } \\
\text { /month): } \\
\lambda_{i}\end{array}$ & $\begin{array}{l}\text { Expected } \\
\text { value of } \\
\text { storing } \\
(\$): \Delta_{i}\end{array}$ \\
\hline$\theta$ & 649 & 679.00 & 64.20 & 10.0 & 646.57 & 220 & 250.00 & 44.38 & 0.1 & 152.02 \\
\hline 1 & 0 & 99999.99 & N/A & 0.0 & 0.00 & 0 & 99999.99 & N/A & 0.0 & 0.00 \\
\hline 2 & 0 & 99999.99 & N/A & 0.0 & 0.00 & 0 & 99999.99 & N/A & 0.0 & 0.00 \\
\hline 3 & 202 & 232.45 & 55.17 & 10.0 & 201.67 & 72 & 102.25 & 37.31 & 0.1 & 48.36 \\
\hline 4 & 42 & 72.45 & 57.83 & 10.0 & 42.29 & 25 & 54.95 & 48.47 & 0.1 & 17.36 \\
\hline 5 & 70 & 100.00 & 65.42 & 10.0 & 69.74 & 47 & 77.45 & 57.94 & 0.1 & 33.90 \\
\hline 6 & 20 & 49.95 & 42.38 & 10.0 & 19.87 & 15 & 44.95 & 37.61 & 0.1 & 10.04 \\
\hline 7 & 25 & 54.95 & 46.56 & 10.0 & 24.85 & 10 & 39.95 & 31.69 & 0.1 & 6.39 \\
\hline 8 & 25 & 54.95 & 46.56 & 10.0 & 24.85 & 20 & 49.95 & 42.73 & 0.1 & 13.70 \\
\hline 9 & 10 & 39.95 & 31.69 & 10.0 & 9.90 & 6 & 35.95 & 24.51 & 0.1 & 3.52 \\
\hline 10 & 20 & 50.00 & 42.78 & 10.0 & 19.92 & 12 & 42.45 & 35.09 & 0.1 & 8.21 \\
\hline 11 & 20 & 49.95 & 42.73 & 10.0 & 19.87 & 17 & 47.45 & 40.50 & 0.1 & 11.87 \\
\hline 12 & 30 & 59.95 & 49.79 & 10.0 & 29.83 & 15 & 44.95 & 37.99 & 0.1 & 10.04 \\
\hline 13 & 15 & 44.95 & 37.99 & 10.0 & 14.89 & 10 & 39.95 & 31.69 & 0.1 & 6.39 \\
\hline 14 & 300 & 329.95 & 95.58 & 10.0 & 298.86 & 142 & 172.45 & 79.86 & 0.1 & 103.74 \\
\hline 15 & 7 & 37.00 & 26.68 & 10.0 & 6.96 & 4 & 33.95 & 19.49 & 0.1 & 2.12 \\
\hline 16 & 75 & 104.95 & 66.91 & 10.0 & 74.67 & 44 & 74.45 & 56.87 & 0.1 & 31.69 \\
\hline 17 & 57 & 87.45 & 61.86 & 10.0 & 57.23 & 17 & 47.45 & 40.50 & 0.1 & 11.87 \\
\hline 18 & 25 & 54.95 & 46.56 & 10.0 & 24.85 & 13 & 42.95 & 35.71 & 0.1 & 8.58 \\
\hline 19 & 25 & 54.95 & 46.56 & 10.0 & 24.85 & 12 & 41.95 & 34.46 & 0.1 & 7.85 \\
\hline 20 & 7 & 37.00 & 26.68 & 10.0 & 6.96 & 5 & 34.95 & 22.18 & 0.1 & 2.81 \\
\hline 21 & 30 & 60.00 & 49.82 & 10.0 & 29.88 & 20 & 49.95 & 42.73 & 0.1 & 13.70 \\
\hline
\end{tabular}

Case 3 shows an absolute demand while Case 4 represents a flexible demand. In this example, customer demand

$D$ is 30 units for any cases. Manual and automatic reassembly processes are considered in Cases 5 and 6 . Table 7

shows the reassembly unit $\operatorname{cost} \rho_{i}$ for assembling Core $\theta$, and Intermediate 1,2 , and 3. In Case $6, \rho_{i}$ is only $\$ 0.1$ per unit for one core and three intermediates as the automated process cost is cheaper than the manual process cost. In particular, the reassembly processes of rear panel assembly (Node 2) and display assembly (Node 3) require many components and adhesive material. Therefore, their reassembly unit costs, $\rho_{2}$ and $\rho_{3}$, are higher than others.

Table 7. Parameter values used in Cases 5 and 6

\begin{tabular}{lrrrr}
\hline & \multicolumn{4}{c}{ Reassembly process unit cost (\$/unit) } \\
\hline & $\rho_{\theta}$ & \multicolumn{1}{c}{$\rho_{1}$} & \multicolumn{1}{c}{$\rho_{2}$} & \multicolumn{1}{c}{$\rho_{3}$} \\
\hline Case 5: Manual reassembly process (M) & 10.0 & 10.0 & \multicolumn{1}{c}{20.0} & 55.0 \\
\hline Case 6: Automated reassembly process (A) & 0.1 & 0.1 & 0.1 & 0.1 \\
\hline
\end{tabular}




\subsection{Results}

The ILP model was solved for all scenarios using Microsoft Excel Solver. Figure 7 visualizes the results of network flows for eight different scenarios. As described in Figure 7-(a), network flow graphs consist of three layers: source node layer, element and reassembly process node layer, and sink node layer. All flows are coming from source nodes and going to sink nodes. As mentioned before, only components nodes have the initial inventory of 20 units represented by flow $x_{\alpha i}$ of 20 units from source node $\alpha$ to component nodes. However, $x_{\alpha i}$ is omitted on the network flow graph to make the networks simple since it is common for all scenarios.

In Layer 2, there are two types of nodes: element nodes and reassembly process nodes. Reassembly process nodes are presented by triangle shape, and have a pair of an intermediate node or a core node. In Figure 7-(b), a triangle with $\hat{\theta}$ is a reassembly process node as a pair of Core Node $\theta$, which means that flows have to go through Reassembly Process $\hat{\theta}$ to reassemble Core $\theta$. In the networks, an arc's thickness represents flow units that are the number of elements moving through the arc. Each scenario's network flow graph has different arcs' direction and thickness, while it has the same node layout. Herein, each arc direction is one of the decision variables, and arc thickness is a value of the decision variable. In Scenario 1 of Figure 7-(b), a decision variable $x_{\theta \omega}$ is 30 flow units moving from Core Node $\theta$ to demand Node $\omega$, which means that 30 units of a core are reassembled to satisfy a demand.

For the scenarios including the latest product case, keeping elements is usually dominant over reassembly for satisfying a demand. This is clearly elucidated by comparing Scenario 1 including the case of the latest product and Scenario 5 involving the case of the obsolete product. In Scenario 1, 15 flow units are from component nodes to inventory (keeping), $\psi$, while all 20 flow units from component nodes in Scenario 5 are heading to reassembly process nodes. This is similarly displayed in a comparison of Scenarios 2 and 6. This directly results from the point that elements of the latest model have higher potential values for storing, $\Delta_{i}$, than the obsolete model as shown in Table 6, largely due to the fact that the latest model case has higher current market values, $\gamma_{i}(0)$. 
Scenarios 1, 2, 5, and 6 include the absolute demand case, where Equation (4) forces flow from Core Node $\theta$ to Demand Node $\omega$. As customer demand $D$ is 30 units, this mandatory demand forces to reassemble or procure elements for making 30 cores even under insufficient inventory levels.

On the networks, the flows going to reassembly process nodes are inhibited by the reassembly process cost. Therefore, in the case of manual reassembly process, the flows have fewer units since they have higher reassembly cost than the automated case. In Figure 7, this is clearly presented in the networks of Scenarios 7 and 8. In Scenario 8, 20 flow units coming from component nodes 5 and 6 are heading to reassembly process node $\widehat{3}$ and then element node 3. Since then, the flows enter inventory (store) node $\psi$ while, in Scenario 7, the 20 flow units are directly heading to $\psi$.

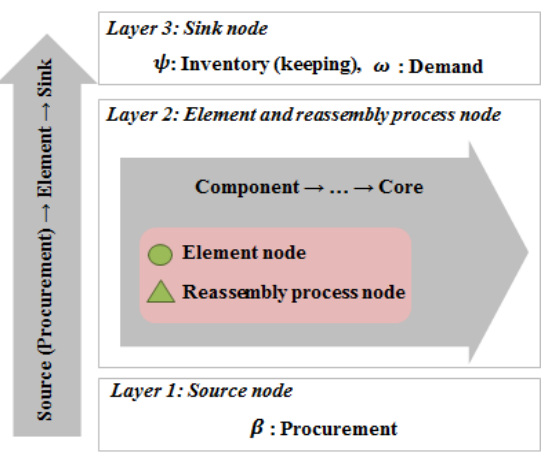

(a) Network flow direction and layer

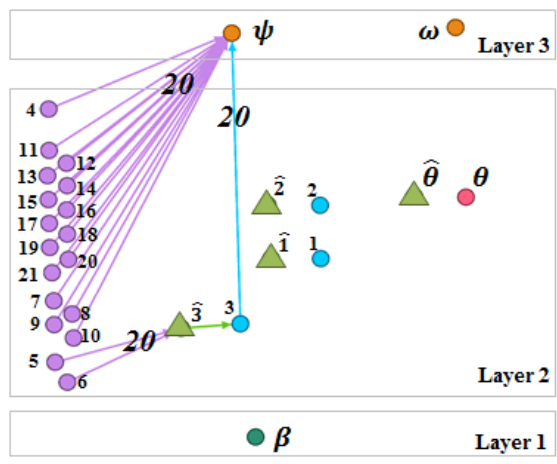

(d) Scenario 3: L.F.M.

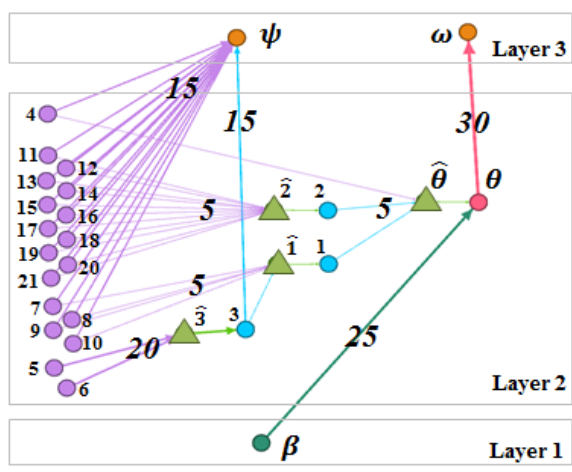

(b) Scenario 1: L.A.M.

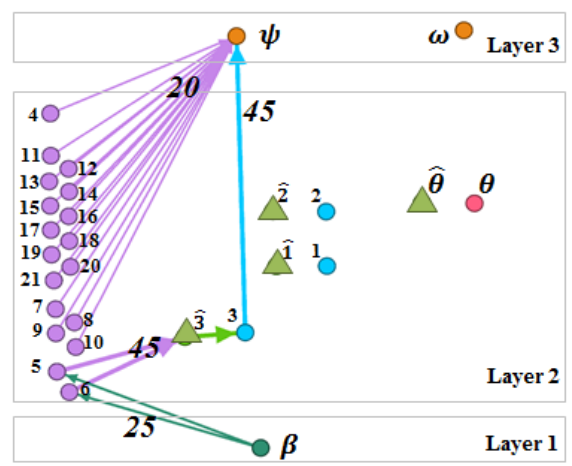

(e) Scenario 4: L.F.A.

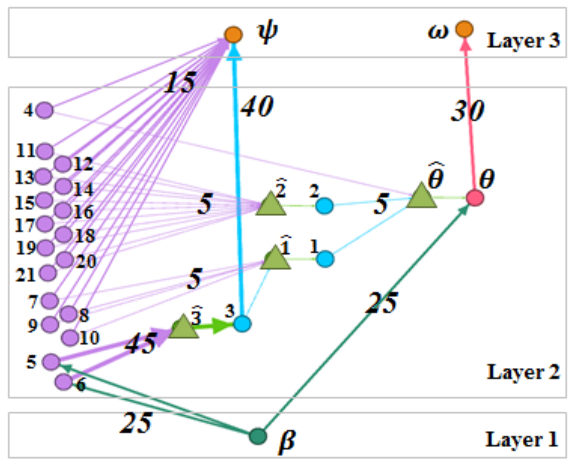

(c) Scenario 2: L.A.A.

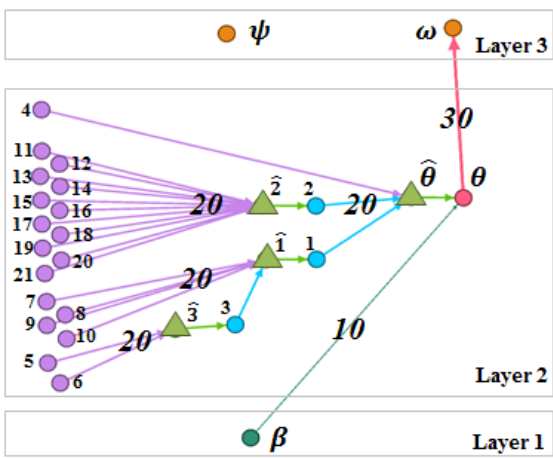

(f) Scenario 5: O.A.M. 


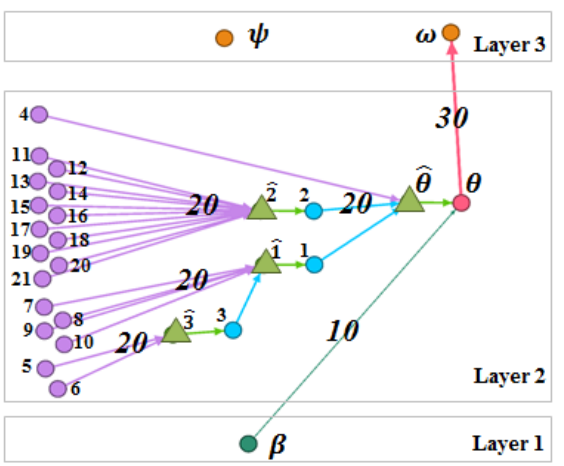

(g) Scenario 6: O.A.A.

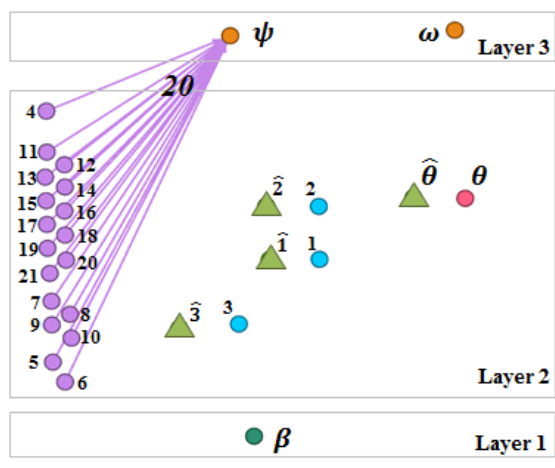

(h) Scenario 7: O.F.M.

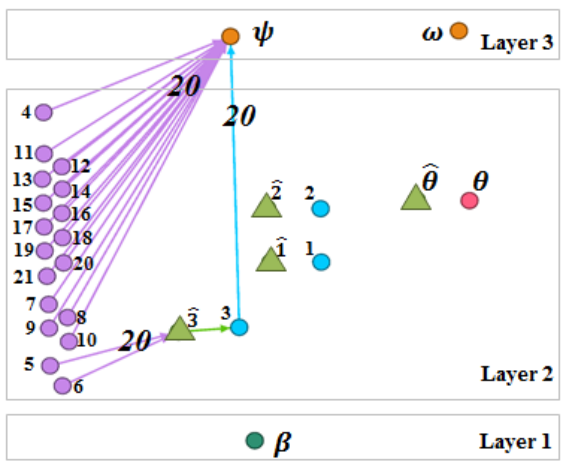

(i) Scenario 8: O.F.A.

Figure 7. The resulting network flow for each scenario

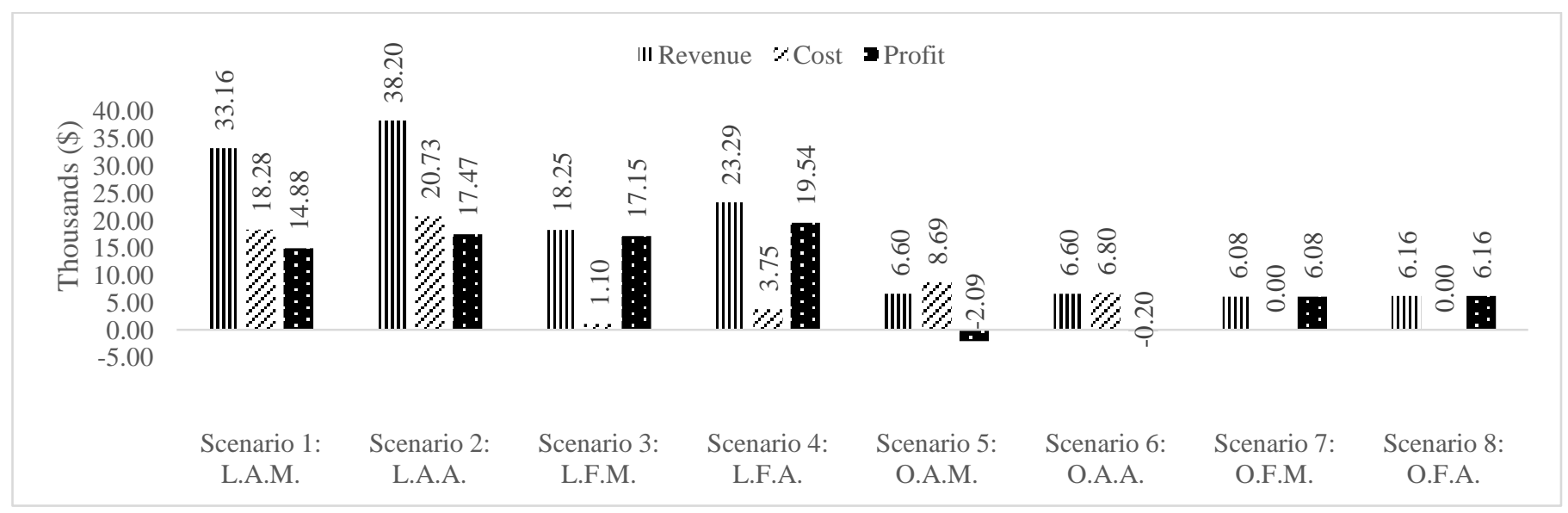

Figure 8 . The revenue, cost and profit for each scenario

Figure 8 shows the revenue, cost, and profit for each scenario. Profits are computed by Equation (1), namely the objective function. Obviously, profits of Scenarios 1, 2, 3 and 4 are higher than others. This is because the scenarios contain the case of the latest model generating higher revenues. This is confirmed in Figure 9, where it displays the internal revenue portions consisting of the demand revenue as a result of selling cores in the market and the keeping revenue which is the expected value of storing elements for future demand or recycling revenue. As shown in Figure 9, Scenarios 1, 2, 3 and 4 have relatively high demand and keeping revenues.

In Figure 8, the costs of Scenario 1, 2, 5, and 6 are pretty high. This is due to the point that under the insufficient inventory situation, absolute demands force remanufacturers to either reassemble elements or to procure elements 
from suppliers. Figure 10 further represents the internal portions of costs: each expense of reassembly and procurement. In the figure, the portion of procurement costs in Scenarios 1, 2, 5, and 6 is dominant over reassembly costs, since there are not sufficient elements in the inventory for reassembly, which leads to procure a certain amount of elements from suppliers.

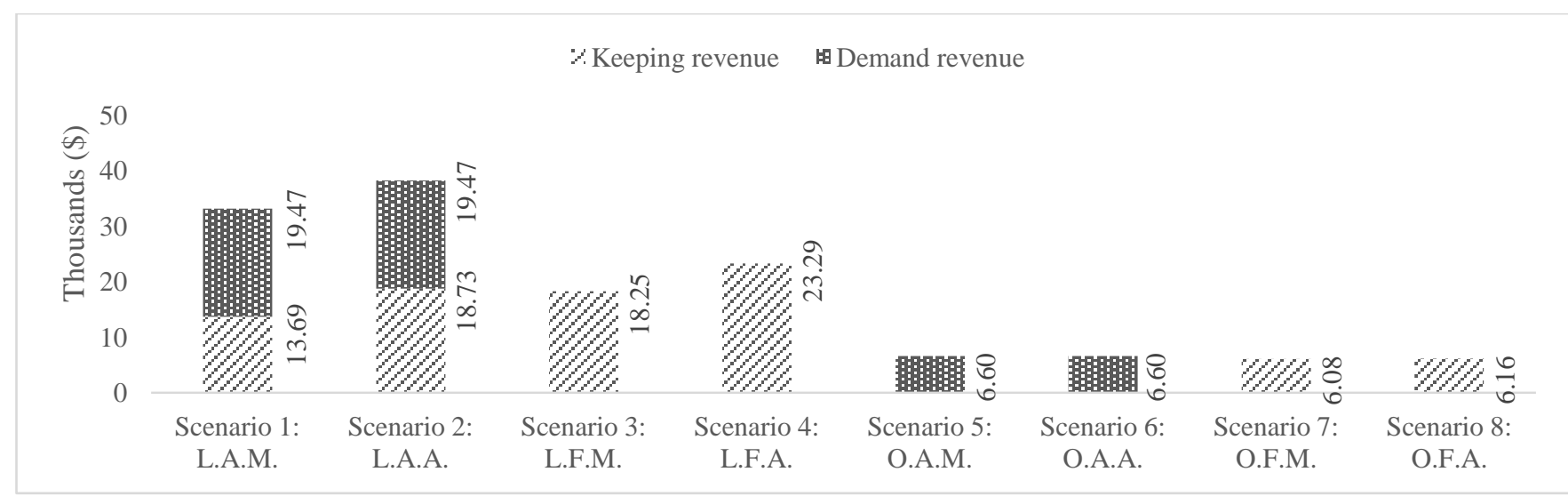

Figure 9. The demand and keeping revenues for each scenario

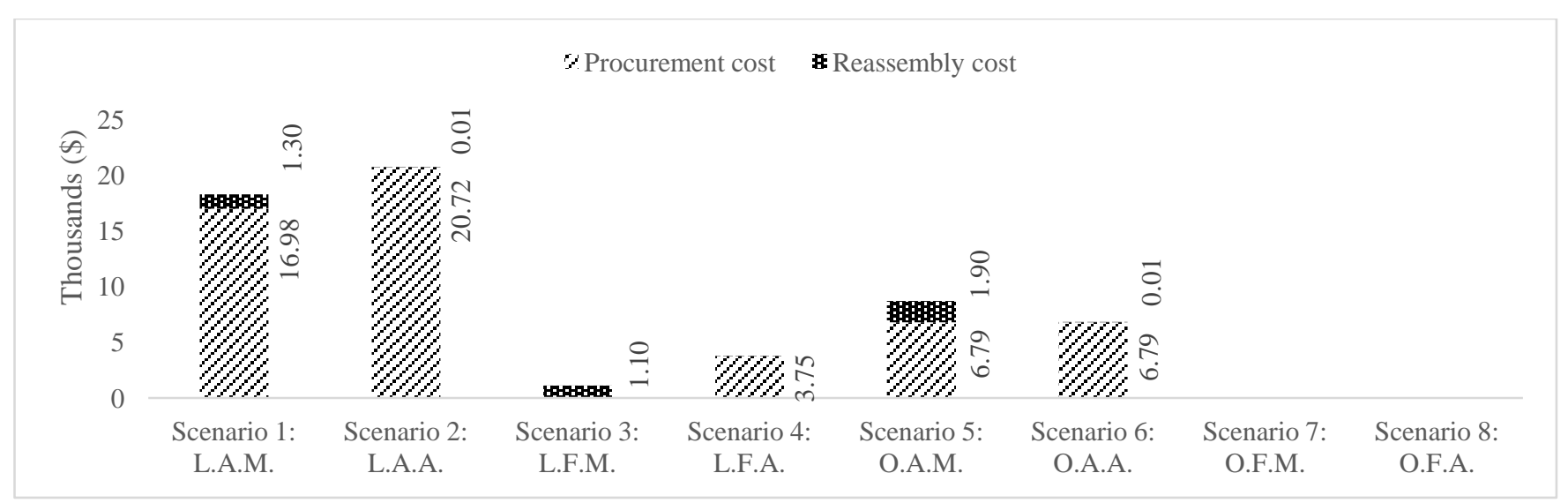

Figure 10. The procurement and reassembly cost for each scenario

In the example, there are four reassembly processes to make Core $\theta$ and Intermediates 1, 2, and 3. Each one has its corresponding reassembly threshold $\rho_{i}^{*}$ and reassembly unit profit $p_{i}$. Table 8 represents $\rho_{i}, \rho_{i}^{*}$ and $p_{i}$ for Scenario 7. $\rho_{i}^{*}$ and $p_{i}$ are computed by Equation (15) and Equation (16), respectively. For Node 3, $\rho_{3}, \$ 55$, is greater than $\rho_{3}^{*}, \$ 4.42$, therefore, the reassembly unit cost is over the threshold. This means that if the reassembly 

are negative, meaning that profits are never going to be made within these reassembly processes since the reassembly cost is always greater than or equal to the threshold. The reassembly profit, $p_{\theta}, \$ 192.63$, can only be generated when Intermediates 1 and 2, and Component 4 are reassembled into Core $\theta$. However, in the example, there is no initial inventory for Intermediates 1 and 2, therefore these elements should be procured or reassembled. Due to the fact that Intermediates 1 and 2 have no market in this problem, they cannot be procured. Thus, reassembly is the only option to fulfill them. However, as mentioned earlier, the reassembly process of Intermediates 1 and 2 generates losses as much as $p_{1}$ and $p_{2},-\$ 90.18$ and $-\$ 230.66$. Although the reassembly profit of $p_{\theta}$ should overcome these losses to make Intermediates 1 and 2, the profit is less than the sum of losses. As a result, without any reassembly, all flow units are going to inventory (store) node $\psi$ in Scenario 7 of Figure 8(h).

Table 8. Reassembly threshold and reassembly unit profit for Scenario 7

\begin{tabular}{lcccr}
\hline Node $i$ & $\theta$ & 1 & 2 & \multicolumn{1}{c}{3} \\
\hline Reassembly unit cost (\$/unit): $\rho_{i}$ & 10.00 & 10.00 & 20.00 & 55.00 \\
\hline Reassembly threshold (\$/unit): $\rho_{i}^{*}$ & 202.63 & -80.18 & -210.66 & 4.42 \\
\hline Reassembly unit profit (\$/unit): $p_{i}$ & 192.63 & -90.18 & -230.66 & -50.58 \\
\hline
\end{tabular}

\section{Conclusion}

The ATO remanufacturing systems have several distinctive characteristics including a high degree of uncertainty in the quality and quantity of incoming products, market demands for both cores and assemblies, and the part value depreciation over time due to technological obsolescence. Along these lines, the current study models an ILP based on a network flow diagram to determine the number and type of parts that should be reassembled and purchased in the ATO-based remanufacturing systems. The study also proposes the concepts of disposal point and reassembly threshold. The disposal point considers the trade-off between recycling benefits and holding costs, and help remanufacturers make proper decisions about the timing for dispose of parts that are stored in the inventory. 
The reassembly threshold makes remanufacturers recognize a tipping point of reassembly cost where they have to keep parts rather than to conduct reassembly.

An illustrative example of a smartphone is provided. Eight different scenarios have been investigated to extract clear results from several contrasting situations: latest and obsolete products, absolute and flexible demands, and manual and automated reassembly processes. Since the absolute demand forces excessive reassembly and procurement under the insufficient inventory, it might reduce the remanufacturer's total profit. In general, latest products generate more profits than obsolete products. Keeping elements for reselling parts in the market might be better than reassembly for a core demand in the case of manual processes due to high reassembly costs.

This work can be extended in several ways. The numerical example can be enhanced by feeding real data including holding cost, recycling benefit, disposal cost and demands. The concept of reassembly threshold can be extended to other parameters such as procurement cost or holding cost. The model can be improved to consider the reassembly process for a product family rather than one product model. The variability in the quality of components as well as the quantity and timing of available supplies can be included in future models. The scope of the work can be extended to include disassembly as well as reassembly. Finally, the model can be generalized into multi-periods decision making model by introducing new methods that can keep track of some variables such as the disposal point whenever a new demand occurs.

\section{Acknowledgements}

This material is based upon work supported by the National Science Foundation - USA under grant \#\#CMMI1435908. Any opinions, findings, and conclusions or recommendations expressed in this material are those of the authors and do not necessarily reflect the views of the National Science Foundation.

\section{References}

[1] X. Jin, "Modeling and analysis of remanufacturing systems with stochastic return and quality variation.," Doctoral Dissertation, The University of Michigan, 2012. 
[2] J. Meredith and U. Akinc, "Characterizing and structuring a new make-to-forecast production strategy," J. Oper. Manag., vol. 25, no. 3, pp. 623-642, Apr. 2007.

[3] S. M. R. Iravani, K. L. Luangkesorn, and D. Simchi-Levi, "On assemble-to-order systems with flexible customers," IIE Trans., vol. 35, no. 5, pp. 389-403, May 2003.

[4] X. Jin, J. Ni, and Y. Koren, "Optimal control of reassembly with variable quality returns in a product remanufacturing system,” CIRP Ann. - Manuf. Technol., vol. 60, no. 1, pp. 25-28, 2011.

[5] X. Jin, S. J. Hu, J. Ni, and G. Xiao, "Assembly strategies for remanufacturing systems with variable quality returns,” IEEE Trans. Autom. Sci. Eng., vol. 10, no. 1, pp. 76-85, Jan. 2013.

[6] M. A. Ilgin and S. M. Gupta, Remanufacturing modeling and analysis. CRC Press, 2012.

[7] B. Esmaeilian, S. Behdad, and B. Wang, "The evolution and future of manufacturing: a review," $J$. Manuf. Syst., vol. 39, pp. 79-100, Apr. 2016.

[8] M. Sabbaghi, S. Behdad, and J. Zhuang, "Managing consumer behavior toward on-time return of the waste electrical and electronic equipment: A game theoretic approach," Int. J. Prod. Econ., vol. 182, pp. 545-563, Dec. 2016.

[9] S. Nahmias, Production and operations analysis, 6th ed. McGraw-Hill/Irwin, 2008.

[10] M. Kwak and H. M. Kim, "Assessing product family design from an end-of-life perspective," Eng. Optim., vol. 43, no. 3, pp. 233-255, Mar. 2011.

[11] M. L. Junior and M. G. Filho, "Production planning and control for remanufacturing: literature review and analysis," Prod. Plan. Control, vol. 23, no. 6, pp. 419-435, Jun. 2012.

[12] A. R. Mashhadi, B. Esmaeilian, and S. Behdad, "Uncertainty management in remanufacturing decisions: a consideration of uncertainties in market demand, quantity, and quality of returns," ASCE-ASME J. Risk Uncertain. Eng. Syst. Part B Mech. Eng., vol. 1, no. 2, pp. 021007-021007, Apr. 2015.

[13] J. (Roger) Jiao, T. W. Simpson, and Z. Siddique, "Product family design and platform-based product development: a state-of-the-art review," J. Intell. Manuf., vol. 18, no. 1, pp. 5-29, Jul. 2007.

[14] K. Park and G. E. Okudan Kremer, "Assessment of static complexity in design and manufacturing of a product family and its impact on manufacturing performance," Int. J. Prod. Econ., vol. 169, pp. 215-232, Nov. 2015.

[15] K. Inderfurth, S. Vogelgesang, and I. M. Langella, "How yield process misspecification affects the solution of disassemble-to-order problems," Int. J. Prod. Econ., vol. 169, pp. 56-67, Nov. 2015.

[16] E. Kongar and S. M. Gupta, "Disassembly to order system under uncertainty," Omega, vol. 34, no. 6, pp. 550-561, Dec. 2006.

[17] E. Kongar and S. M. Gupta, "Solving the disassembly-to-order problem using linear physical programming," Int. J. Math. Oper. Res., vol. 1, no. 4, pp. 504-531, Jan. 2009.

[18] S. M. Gupta, P. Imtanavanich, and K. Nakashima, "Using neural networks to solve a disassemblyto-order problem," Int. J. Biomed. Soft Comput. Hum. Sci., vol. 15, no. 1, pp. 65-69, Apr. 2010.

[19] R. Geyer and T. Jackson, "Supply loops and their constraints: the industrial ecology of recycling and reuse," Calif. Manage. Rev., vol. 46, no. 2, pp. 55-73, Jan. 2004.

[20] S. K. Mukhopadhyay and H. Ma, "Joint procurement and production decisions in remanufacturing under quality and demand uncertainty," Int. J. Prod. Econ., vol. 120, no. 1, pp. 5-17, Jul. 2009.

[21] G. C. Souza and M. E. Ketzenberg, "Two-stage make-to-order remanufacturing with service-level constraints,” Int. J. Prod. Res., vol. 40, no. 2, pp. 477-493, Jan. 2002. 
[22] G. W. DePuy, J. S. Usher, R. L. Walker, and G. D. Taylor, "Production planning for remanufactured products," Prod. Plan. Control, vol. 18, no. 7, pp. 573-583, Oct. 2007.

[23] G. C. Souza, "Production planning and control for remanufacturing," in Closed-loop Supply Chains: New Developments to Improve the Sustainability of Business Practices, Boca Raton : CRC Press, 2010, pp. 119-130.

[24] Y. Pochet and L. A. Wolsey, Production Planning by Mixed Integer Programming, 2006 edition. Berlin; New York: Springer, 2006.

[25] V. Jayaraman, "Production planning for closed-loop supply chains with product recovery and reuse: an analytical approach,” Int. J. Prod. Res., vol. 44, no. 5, pp. 981-998, Mar. 2006.

[26] A. Xanthopoulos and E. Iakovou, "On the optimal design of the disassembly and recovery processes," Waste Manag., vol. 29, no. 5, pp. 1702-1711, May 2009.

[27] K. Rosling, "Optimal inventory policies for assembly systems under random demands," Oper. Res., vol. 37, no. 4, pp. 565-579, 1989.

[28] K. Fu, V. N. Hsu, and C.-Y. Lee, "Inventory and production decisions for an assemble-to-order system with uncertain demand and limited assembly capacity," Oper. Res., vol. 54, no. 6, pp. 11371150, 2006.

[29] A. Persona, D. Battini, R. Manzini, and A. Pareschi, "Optimal safety stock levels of subassemblies and manufacturing components," Int. J. Prod. Econ., vol. 110, no. 1-2, pp. 147-159, Oct. 2007.

[30] S. Benjaafar and M. ElHafsi, "Production and inventory control of a single product assemble-toorder system with multiple customer classes," Manag. Sci., vol. 52, no. 12, pp. 1896-1912, Dec. 2006.

[31] M. ElHafsi, "Optimal integrated production and inventory control of an assemble-to-order system with multiple non-unitary demand classes," Eur. J. Oper. Res., vol. 194, no. 1, pp. 127-142, Apr. 2009.

[32] M. F. Keblis and Y. Feng, "Optimal pricing and production control in an assembly system with a general stockout cost," IEEE Trans. Autom. Control, vol. 57, no. 7, pp. 1821-1826, 2012.

[33] K. L. Gunter, "Inventory and value management in demanufacturing facilities," Doctoral Dissertation, Michigan Technological University, Ann Arbor, United States, 2004.

[34] E. Bazan, M. Y. Jaber, and S. Zanoni, "A review of mathematical inventory models for reverse logistics and the future of its modeling: an environmental perspective," Appl. Math. Model., vol. 40, no. 5-6, pp. 4151-4178, Mar. 2016.

[35] R. Haijema, "Optimal ordering, issuance and disposal policies for inventory management of perishable products," Int. J. Prod. Econ., vol. 157, pp. 158-169, Nov. 2014.

[36] G. E. Marttn, “An optimal decision model for disposal of perishable inventories," Int. J. Prod. Res., vol. 24, no. 1, pp. 73-79, Jan. 1986.

[37] S. Nahmias, "Perishable inventory theory: a review," Oper. Res., vol. 30, no. 4, pp. 680-708, 1982.

[38] V. D. R. Guide, G. C. Souza, L. N. V. Wassenhove, and J. D. Blackburn, "Time value of commercial product returns,” Manag. Sci., vol. 52, no. 8, pp. 1200-1214, Aug. 2006.

[39] M. Kwak, H. Kim, and D. Thurston, "Formulating second-hand market value as a function of product specifications, age, and conditions," J. Mech. Des., vol. 134, no. 3, pp. 032001-032001, Mar. 2012. 
[40] R. K. Ahuja, T. L. Magnanti, and J. B. Orlin, Network flows: theory, algorithms, and applications, 1 edition. Englewood Cliffs, N.J: Prentice Hall, 1993.

[41] K. Huang, "Maximum flow problem in assembly manufacturing networks," Doctoral Dissertation, North Carolina State University, 2011.

[42] V. D. R. Guide Jr., "Production planning and control for remanufacturing: industry practice and research needs," J. Oper. Manag., vol. 18, no. 4, pp. 467-483, Jun. 2000.

[43] S. M. Ross, Introduction to probability models, Eleventh edition. Academic Press, 2014. 